\title{
Mutational Analysis of Quinolone-Resistant Determining Region gyrA and parc Genes in Quinolone-Resistant ESBL-Producing E. Colf
}

\author{
Sirat $\mathrm{R}^{\mathrm{a}, \mathrm{b}}$, Hamzah HA ${ }^{\mathrm{a}}$, A. Mustafa Mahmud $\mathrm{MI}^{\mathrm{a}}$, Baharudin $\mathbf{R}^{\mathrm{c}}$ \\ ${ }^{a}$ Department of Basic Medical Sciences, Kulliyyah of Medicine, International Islamic University Malaysia (IIUM), Kuantan, Pahang Darul Makmur \\ ${ }^{b}$ Department of Para-clinic, Medicine Faculty and Teaching Hospital, Kandahar University, Kandahar province, Afghanistan \\ 'Department of Pathology, Hospital Tengku Ampuan Afzan, Kuantan Pahang, Malaysia
}

Keywords

quinolones, beta-Lactamases, Escherichia coli, antimicrobial resistance, hospital

Corresponding Author

Assoc. Prof. Dr. Hairul Aini Hamzah

Department of Basic Medical Sciences, Kulliyyah of Medicine,

International Islamic University Malaysia

(IIUM), Bandar Indera Mahkota,

Jalan Sultan Ahmad Shah,

25200 Kuantan, Pahang Darul Makmur,

Malaysia.

Tel: +609-571 4000

Email: hairulaini@iium.edu.my

Received: 26 February 2021; Accepted: 14 June 2021

Doi: https://doi.org/10.31436/imjm.v20i3

\section{ABSTRACT}

INTRODUCTION: Introduction: Co-resistance to quinolones among extended spectrum $\beta$ lactamase (ESBL)-producing E. coli commonly occurs in clinical settings. Quinolones act on DNA gyrase and DNA topoisomerase enzymes, which are coded by gyrA and parC genes, thus any mutation to the genes may affect the drug effectiveness. The objective of the study was to characterize gyr $A$ and $\operatorname{par} C$ genes in quinolone-resistant E. coli isolates and correlated the mutations with their phenotypic resistance. MATERIALS AND METHODS: Thirty-two quinolone-resistant (QR) and six quinolone-sensitive (QS) ESBLE. coli isolates were identified by antibiotic susceptibility and minimum inhibitory concentration tests. Bioinformatics analysis were conducted to study any mutations occurred in the genes and generate their codon compositions. RESULTS: All the QR ESBL-E. coli isolates were identified as multidrug-resistant bacteria. A single point mutation in the quinolone resistance-determining region (QRDR) ofgyrA, at codon 83, caused the substitution amino acid Ser83Leu. It is associated with a high level of resistance to nalidixic acid. However, double mutations Ser83Leu and Asp87Asn in the same region were significantly linked to higher levels of resistance to ciprofloxacin. Cumulative point mutations in gyr $A$ and/or in $\operatorname{par} C$ were also correlated significantly $(\mathrm{p}<0.05)$ to increased resistance to ciprofloxacin. CONCLUSION: Together, the findings showed that the mutations in gyrA and parC genes handled the institution of intrinsic quinolone resistance in the ESBL-E. coli isolates. Thus, vigilant monitoring for emergence of new mutation in resistance genes may give an insight into dissemination of QR ESBLE. coli in a particular region.

\section{INTRODUCTION}

Escherichia coli is a member of the family Enterobacteriaceae and is commonly associated with antibiotic resistance in many regions, thus creates concerns globally. The pathogen, whose normal habitats are the intestinal tract of humans and animals, are frequently associated with serious nosocomial as well as community-acquired infections such as pneumonia, sepsis, urinary tract infections, and several intra-abdominal infections. Although most are harmful, some strains of this species are related to a variety of antibiotic resistance genes acquired by the horizontal transfer of plasmids, pathogenicity islands, transposons, and bacteriophages. ${ }^{1,2}$ Therefore, treatment and management of $E$. coli infections are commonly complicated by the appearance of resistance to multiple antibiotics and even to all currently known antibiotics. These multiple-drug resistant (MDR) E. coli strains are routinely discovered in many diagnostic laboratories by phenotypic testing.

MDR E. coli has commonly associated with the acquisition of extended-spectrum ß-lactamase (ESBL) determinants that give rise to the development of resistance to all B-lactam antibiotics except 
carbapenems and cephamycins. Outbreaks of ESBLproducing $E$. coli in healthcare settings have been reported by many. 3,4 Consequently, the increased prevalence of MDR E. coli strains has resulted in substantial usage of other antimicrobials including quinolones and fluoroquinolones (FQs). Among FQs, ciprofloxacin is one of the most used antibiotics to treat E. coli infection, thus resistance to the drug is on the rise. In Malaysia, the prevalence of ciprofloxacin resistance among E. coli isolates from all types of clinical samples is considered high, which is around $23.4 \%$ - to $24.1 \% .^{5}$ Mechanism of ciprofloxacin resistance among ESBL-producing Enterobacteriaceae such as Klebsiella pneumoniae has been reported before but studies on quinolone resistance among E. coli are rare. ${ }^{6}$

As for the mechanism of action, quinolone targets DNA gyrase and DNA topoisomerase enzymes which are essential for normal bacterial growth and proliferation. The DNA gyrase subunits are encoded by gyr $A$ and gyrB genes and are known as the primary quinolone target in gram-negative bacteria, while DNA topoisomerase IV, encoded by parC and parE genes, is a secondary target but reversely applies to gram-positive bacteria. ${ }^{7}$ DNA gyrase is an essential regulator of DNA supercoiling and relieves topological stress arising from DNA replication complexes meanwhile, topoisomerase IV unwinds and decatenates newly replicated chromosomes following the bacterial DNA replication process. Thus, changes such as single nucleotide mutation of the genes may confer resistance to quinolone drugs by the bacterial cells. ${ }^{8,9}$

Genetic mechanisms of quinolone resistance may also be mediated by plasmid bearing one or multiple genes such as $q n r A$, qnrB, and $q n r C .{ }^{10}$ These genes encode for proteins that protect DNA gyrase and topoisomerase IV from quinolone inhibition. Studies have shown that the quinolone-resistant bacteria may confer varying degrees of resistance either chromosomally or plasmidmediated or in combination. 8,9 Among these resistance mechanisms, target-mediated resistance caused by specific mutations in the genes coding for subunits of DNA gyrase $(\operatorname{gyr} A)$ and topoisomerase IV (parC), is commonly reported worldwide. ${ }^{11-14}$ These resistance mutations often occur in a region called the quinolone resistance determining region (QRDR) in the encoded gene, which is in close proximity to the amino-terminal domain. Although plasmids-mediated resistance may still enhance the selection of high resistance organisms, mutations in $g y r A$ are the primary cause of quinolone resistance encountered in gram-negative clinical isolates. ${ }^{6,12,15}$

A study on antibiotic resistance among bacterial pathogens is important in the decision making of treatment intervention in a hospital setting. Many studies on the prevalence of antibiotic resistance among E. coli in Malaysia have been done but only a few focused on the quinolone resistance among $E$. coli clinical isolates. ${ }^{16}$ Further investigation of the genetic mechanism of resistance would give insights into the evolutionary dynamics of clinical isolates of E. coli from quinolone susceptible to resistance. As local data on the genetic mechanism of quinolone resistance was scarce, we aimed to characterize the molecular mechanism for quinolone resistance being developed among ESBL-E. coli in Hospital Tengku Ampuan Afzan (HTAA), Pahang, Malaysia. We examined the nucleotide sequences of the DNA chromosomal gyrA and parC genes among the isolates because mutations in the genes are the main cause of quinolone resistance. Furthermore, we also studied the antibiotic susceptibility pattern of the isolated bacteria which were also identified as the MDR E. coli.

\section{MATERIAL \& METHOD}

\section{Bacterial Isolates}

The sample size was calculated using an online application, OpenEPi (http://www.openepi.com). The sample size for a proportion or descriptive study was chosen with the desired absolute precision of 0.05 and 98\% prevalence of gyrA gene mutation in quinoloneresistant E. coli. A minimum of 30 bacterial isolates was required for the mutational analysis study.

A total of 43 bacterial isolates, which were presumed as ESBL-producing E. coli isolates, were collected through a process convenience sampling method over 3 months (September to November 2018) from the Pathology Laboratory at HTAA, Kuantan, Pahang. Isolates were obtained from various types of clinical specimens such as urine, blood, swabs, tracheal aspirates, tissue, and 
endotracheal tube which were collected from outpatients and inpatients of different wards. HTAA is a tertiary hospital in Pahang and a referral for many district hospitals within Pahang as well as certain regions of southern Terengganu.

All isolates were then labelled by number and reidentified at our laboratory by phenotypic and conventional tests such as, Gram's staining, IMViC test, combination disc test for phenotypic ESBL detection, analytical profile index (API 20E) identification system (BioMerieux, France), and applying of nalidixic acid and ciprofloxacin discs by Kerby-Bauer antibiotic sensitivity testing method, as well as determining of MICs of nalidixic acid and ciprofloxacin by applying E-test strip. Throughout the procedures, E. coli ATCC 25922 was used in tandem as a negative control. Bacterial isolates which were resistant to nalidixic acid or ciprofloxacin or both were identified as quinolones-resistant (QR) E. coli. Upon reidentification, 38 out of 43 isolates were confirmed as the ESBL E. coli which 32/38 were QR and 6/38 were quinolones-sensitive (QS). The other $5 / 43$ isolates (isolates $7,8,18,20$, and 25) were excluded from the study. The study was approved by the Medical Research Ethics Committee (MREC 18-1378, Ministry of Health, Malaysia).

\section{Antibiotic Susceptibility and Minimum Inhibitory Concentration}

Susceptibility to different antimicrobials was performed by Kirby-Bauer disc diffusion method on MuellerHinton agar (MHA) and was interpreted according to Clinical and Laboratory Standards Institute (CLSI) recommendations. ${ }^{17}$ Tested antibiotics included ampicillin $(10 \mu \mathrm{g})$, cefotaxime $(30 \mu \mathrm{g})$, ceftazidime (30 $\mu \mathrm{g})$, cefepime $(30 \mu \mathrm{g})$, imipenem $(10 \mu \mathrm{g})$, meropenem $(10 \mu \mathrm{g})$, ertapenem $(10 \mu \mathrm{g})$, piperacillin-tazobactam $(100 / 10 \mu \mathrm{g})$, gentamicin $(30 \mu \mathrm{g})$, amikacin $(30 \mu \mathrm{g})$, nalidixic acid $(30 \mu \mathrm{g})$, ciprofloxacin $(5 \mu \mathrm{g})$, tetracycline (30 $\mu \mathrm{g})$, trimethoprim-sulfamethoxazole (1.25/23.75 $\mu \mathrm{g})$ and colistin $(10 \mu \mathrm{g})$ (Oxoid Ltd., Basingstoke, UK).

Minimum inhibitory concentrations (MICs) of nalidixic acid and ciprofloxacin were determined by E-test strips (Liofilchem s.r.l., Italy) according to CLSI guidelines. The isolates were considered resistant to nalidixic acid and ciprofloxacin if their MIC values were $\geq 32 \mu \mathrm{g} / \mathrm{mL}$ and $\geq 4 \mu \mathrm{g} / \mathrm{mL}$, respectively. Isolates showing resistance to more than three different classes of antimicrobials were defined as MDR E. coli according to the previous terminology. The ESBL E. coli strains were identified phenotypically by a combined disc diffusion test according to the CLSI guidelines. Isolates that showed resistance to oxyimino-cephalosporins (ceftazidime and/or cefotaxime) were considered as putative ESBL E. coli.

\section{Amplification of gyrA and parC gene}

Genomic DNA from all bacterial samples was extracted from $5 \mathrm{~mL}$ of overnight grown culture using Presto $^{\mathrm{TM}}$ mini gDNA bacteria kit (Geneaid Biotech Ltd, Taiwan) according to the manufacturer's protocol. The target regions of $g y r A$ and $\operatorname{par} C$ genes were amplified with exTEN 2x Master Mix PCR kit (1 ${ }^{\text {st }}$ BASE, Apical Scientific Sdn Bhd., Malaysia), which the primer sets used and the PCR conditions were previously described by $\mathrm{Hu}$ et al. ${ }^{18}$ PCR reaction mixture without DNA template was served as nontemplate control.

\section{DNA sequencing and data analysis}

Amplified PCR products of gyr $A$ and parC genes were sequenced by the Sanger DNA sequencing method (DNA sequencing plus, $1^{\text {st }}$ Base, Apical Scientific, Selangor, Malaysia). Mutations in QRDRs were identified by comparing the sequencing data with those of the E. coli K-12 strain (GenBank accession no. U00096.3) using the NCBI BLAST program (NCBI, USA), Clustal W Multiple Sequence Alignment Program (Bioedit Sequence Alignment Editor, version 7.2.5) and the Codon Code Sequence Assembly and Alignment Software (CodonCode, Corp, Centervilli, MA, USA). Statistical analyses were performed using SPSS software version 22 (SPSS Inc., Chicago, IL). Descriptive data were expressed as percentage frequency. The association between the number of amino acid mutations in the respective QRDRs and ciprofloxacin MICs was analysed by Pearson's correlation coefficient test and $\mathrm{p}<0.05$ was considered significant. 


\section{RESULTS}

\section{Antibiotic susceptibility profile}

Thirty-eight (38) ESBL-E. coli isolates were obtained from urine $(50 \%)$, blood $(28.9 \%)$, $(10.5 \%)$, tracheal aspirates $(5.3 \%)$, tissue $(2.6 \%)$, and endotracheal tube (2.6\%), which 32/38 and 6/38 were QR and QS isolates, respectively. Antimicrobial susceptibility to 15 antibiotics (Table 1) was determined and the result showed that all $32 \mathrm{QR}$ isolates were resistant to nalidixic acid, ampicillin, and tetracycline. The highest resistance rate was found to cefotaxime (96.9\%) followed by ciprofloxacin (78.1\%), trimethoprimsulfamethoxazole $(75 \%)$, ceftazidime $(56.3 \%)$, cefepime $(43.8 \%)$, and lower resistance was found to gentamicin (25\%). However, no resistance was found to piperacillin-tazobactam, imipenem, meropenem, ertapenem, amikacin and colistin. In terms of quinolones antibiotics susceptibility, 7 out of $32 \mathrm{QR}$ isolates were resistant to ciprofloxacin. Meanwhile, all the 6 QS isolates were $100 \%$ susceptible to piperacillintazobactam, carbapenem, aminoglycosides, and other quinolones used in the experiment. We also found that all the $32 \mathrm{QR}$ isolates were multi-drug resistant bacteria, which most of them had resistance to 6,7 , or 8 antibiotics. The MICs of nalidixic acid were highly increased in all the QR isolates $(\geq 256 \mu \mathrm{g} / \mathrm{ml})$, and 7 of them were also had increased MIC for ciprofloxacin $(\geq$ $4 \mu \mathrm{g} / \mathrm{ml})$.

\section{DNA sequencing analysis of gyrA and parC genes}

Both gyrA and parC genes were amplified by conventional PCR. The targeted DNA was 648 bps for the gyrA gene and $395 \mathrm{bps}$ for the parC gene, respectively, spanning the QRDRs.

The result of BLASTX showed a 100\% identity score with E. coli DNA gyrase and DNA topoisomerase IV. From 32 QR ESBL-E. coli isolates, 96.9\% (31/32) contained at least one resistant point mutation in the QRDR of gyrA gene with a high level of MIC of nalidixic acid $(\geq 256 \mu \mathrm{g} / \mathrm{ml})$. The most common mutation in the QRDR of the gyrA gene was the substitution of cytosine $(\mathrm{C})$ with thymine $(\mathrm{T})$, which

Table I. Antibiotic susceptibility profile of 38 E. coli isolates to commonly used antibiotics.

\begin{tabular}{|c|c|c|c|c|c|c|}
\hline \multirow[t]{3}{*}{ Antibiotic } & \multirow{2}{*}{\multicolumn{3}{|c|}{$\begin{array}{l}\text { Quinolone-resistant ESBL-E.coli }(\mathrm{n}=32) \\
\text { No of isolates, } \mathrm{n}(\%)\end{array}$}} & \multirow{2}{*}{\multicolumn{3}{|c|}{ Quinolone-sensitive ESBL-E.coli $(\mathrm{n}=6)$}} \\
\hline & & & & & & \\
\hline & $* \mathrm{~S}$ & I & $\mathrm{R}$ & S & I & $\mathrm{R}$ \\
\hline \multicolumn{7}{|l|}{$\beta$-lactam } \\
\hline Ampicillin & $0(0)$ & $0(0)$ & $32(100)$ & $0(0)$ & $0(0)$ & $6(100)$ \\
\hline Cefotaxime & $0(0)$ & $1(3.1)$ & $31(96.9)$ & $0(0)$ & $0(0)$ & $6(100)$ \\
\hline Ceftazidime & $4(12.5)$ & $10(31.3)$ & $18(56.3)$ & $3(50)$ & $0(0)$ & $3(50)$ \\
\hline Cefepime & $8(25)$ & $10(31.3)$ & $14(43.8)$ & $3(50)$ & $2(33.3)$ & $1(16.7)$ \\
\hline Piperacillin-Tazobactam & $28(87.5)$ & $4(12.5)$ & $0(0)$ & $6(100)$ & $0(0)$ & $0(0)$ \\
\hline Imipenem & $32(100)$ & $0(0)$ & $0(0)$ & $6(100)$ & $0(0)$ & $0(0)$ \\
\hline Meropenem & $32(100)$ & $0(0)$ & $0(0)$ & $6(100)$ & $0(0)$ & $0(0)$ \\
\hline Ertapenem & $32(100)$ & $0(0)$ & $0(0)$ & $6(100)$ & $0(0)$ & $0(0)$ \\
\hline \multicolumn{7}{|l|}{ Aminoglycosides } \\
\hline Gentamicin & $24(75)$ & $0(0)$ & $8(25)$ & $6(100)$ & $0(0)$ & $0(0)$ \\
\hline Amikacin & $32(100)$ & $0(0)$ & $0(0)$ & $6(100)$ & $0(0)$ & $0(0)$ \\
\hline \multicolumn{7}{|l|}{ Quinolones } \\
\hline Nalidixic acid & $0(0)$ & $0(0)$ & $32(100)$ & $6(100)$ & $0(0)$ & $0(0)$ \\
\hline Ciprofloxacin & $7(21.9)$ & $0(0)$ & $25(78.1)$ & $6(100)$ & $0(0)$ & $0(0)$ \\
\hline \multicolumn{7}{|l|}{ Others } \\
\hline Tetracycline & $0(0)$ & $0(0)$ & $32(100)$ & $1(16.7)$ & $0(0)$ & $5(83.3)$ \\
\hline $\begin{array}{l}\text { Trimethoprim- } \\
\text { Sulfamethoxazole }\end{array}$ & $7(21.9)$ & $1(3.1)$ & $24(75)$ & $4(66.7)$ & $0(0)$ & $2(33.3)$ \\
\hline Colistin & $32(100)$ & $0(0)$ & $0(0)$ & $6(100)$ & $0(0)$ & $0(0)$ \\
\hline
\end{tabular}

*S, sensitive; I, Intermediate; R, Resistant 
resulted in an amino acid substitution of serine (TCG) to leucine (TTG) at position 83 of the amino acid residue $(96.9 \%)$ (Fig. 1). Another mutation in the QRDR of the $g y r A$ gene occurred at position 87 which aspartic acid was substituted to either asparagine $(71.9 \%)$ or tyrosine $(3.1 \%)$.

\begin{tabular}{|c|c|}
\hline & 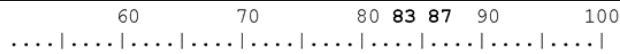 \\
\hline E coli K12 & AMNVLGNDWNKAYKKSARVVGDVIGKYHPHGDSAVYDTIVRMAQPFSLRY \\
\hline QS_12_gYrA & $\ldots \ldots+\cdots, \ldots, \ldots, \ldots$ \\
\hline QS-26_gyrA & 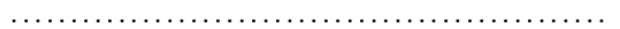 \\
\hline QS_31_9yrA & 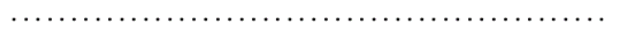 \\
\hline QS_-32_gyrA & (n.m. \\
\hline QS_-38_gyrA & 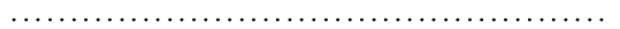 \\
\hline QS_-39_gYrA & \\
\hline $\mathrm{E}$ coli $\mathrm{PU}-1$ & AMNVLGNDWNKAYKKSARVVGDVIGKYHPHGDLAVYDTIVRMAQPFSLRY \\
\hline QR_1_gYrA & $1 n_{1}$ \\
\hline QR_2_gYrA & 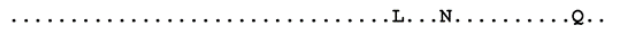 \\
\hline QR_3_gYrA & 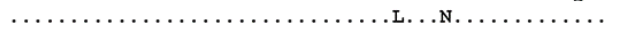 \\
\hline $\mathrm{QR}_{-}^{-}{ }_{-}^{-} \mathrm{gYrA}$ & 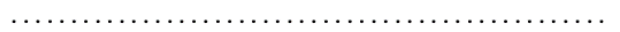 \\
\hline QR_5_gYrA & (n) \\
\hline QR_6_gYrA & 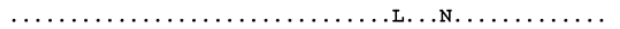 \\
\hline QR_9_gYrA & 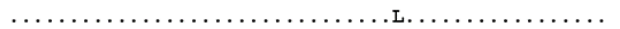 \\
\hline $\mathrm{QR}_{-10}^{-} \mathrm{gYrA}$ & 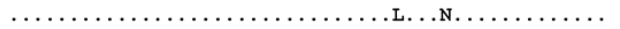 \\
\hline $\mathrm{QR}_{11} \mathrm{gYrA}$ & 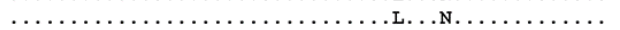 \\
\hline $\mathrm{QR}_{1}^{-} 13$-gYrA & 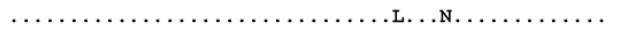 \\
\hline $\mathrm{QR}_{1}^{-} 14$-gYrA & 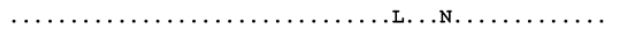 \\
\hline $\mathrm{QR}^{-15} \mathrm{gYrA}$ & 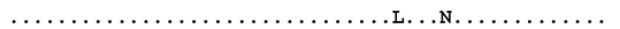 \\
\hline QR_-16_gYrA & 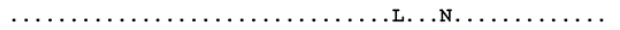 \\
\hline $\mathrm{QR}_{-17}^{-} \mathrm{gYrA}$ & (mon, \\
\hline QR_19_9YYA & 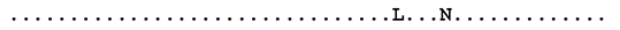 \\
\hline$Q R 219 Y r A$ & 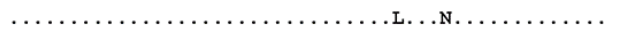 \\
\hline QR_22_gYrA & (n) \\
\hline $\mathrm{QR}_{-}^{-} 23_{-9 \mathrm{YrA}}^{-}$ & 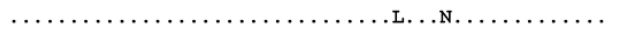 \\
\hline $\mathrm{QR} 24$ - $4 \mathrm{YrA}$ & \\
\hline QR_27_gYrA & \\
\hline $\mathrm{QR}_{-}^{-} 28_{\text {-gYrA }}^{-}$ & 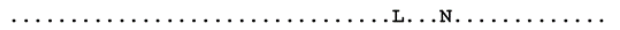 \\
\hline $\mathrm{QR}_{-}^{-} 29$ gYrA & 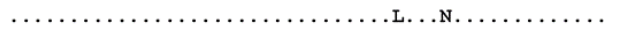 \\
\hline $\mathrm{QR}^{-} 30_{-9 \mathrm{Y} \mathrm{rA}}^{-}$ & 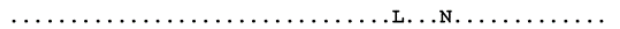 \\
\hline $\mathrm{QR}_{3}^{-} 33_{-} \mathrm{gYYA}$ & 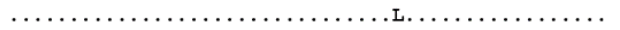 \\
\hline $\mathrm{QR}_{3} 34 \mathrm{gYrA}$ & . $\ldots \ldots \ldots \ldots \ldots \ldots \ldots \ldots$ \\
\hline QR_-35_9YrA & 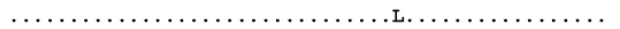 \\
\hline $\mathrm{QR}_{3} 36 \mathrm{gYrA}$ & \\
\hline QR_37_gYrA & \\
\hline $\mathrm{QR}_{4}^{-} 40_{-9 \mathrm{YrA}}^{-}$ & 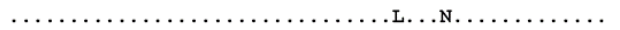 \\
\hline $\mathrm{QR}_{-}^{-} 41_{\text {-gYrA }}^{-}$ & 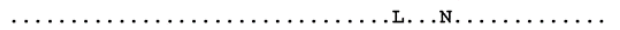 \\
\hline $\mathrm{QR}_{-}^{-} 42_{-}^{-} \mathrm{gYrA}$ & 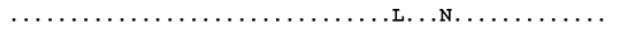 \\
\hline$Q R=9 Y$ gYA & 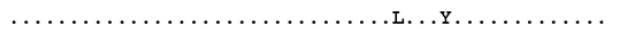 \\
\hline
\end{tabular}

Fig 1. Missense mutations of gyrA gene in the quinolone-resistant (QR) ESBL-E. coli isolates. Partial protein sequence analysis of quinolone-resistant determination region shows amino acid changes at positions 83 and 87 when compared to the quinolone-sensitive (QS) isolates. E. coli K12 strain is the reference strain and represents the QS strain amino acid sequences, while $E$. coli PU-1 represents the QR isolates. The numbering of the amino acid residues was confirmed with the reference strain E. coli K-12 strain. ( $\mathrm{L}=$ leucine, $\mathrm{N}=$ asparagine, $\mathrm{Q}=$ glutamine, $\mathrm{Y}=$ tyrosine)

Of the 32 QR ESBL-E. coli isolates, 26 (81.2\%) contained point mutations in the QRDR of the parC gene (Fig. 2). Five (5) different amino acid substitutions were found in several positions inside and outside of the QRDR of the parC gene. The most common point mutation in the QRDR of the parC gene was the substitution of serine by isoleucine (78.1\%). Another mutation was at codon position 84 where glutamic acid was substituted by valine $(40.6 \%)$ or by glycine $(12.5 \%)$. However, other resistance mutations were also found outside the QRDR of the parC gene such as Val144Met, $(3.1 \%)$ and Asn176Thr, (3.1\%). One isolate (isolate QR_4) with a high MIC of both nalidixic acid $(\geq 256$ $\mu \mathrm{g} / \mathrm{ml}$ ) and ciprofloxacin $(32 \mu \mathrm{g} / \mathrm{ml})$, was found to have no resistance-conferring mutations in neither gyr $A$ nor parC genes. Besides the resistance-associated point mutations, several silent mutations were also found inside and outside of QRDRs in both QR and QS isolates.

\begin{tabular}{|c|c|}
\hline & 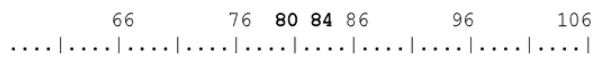 \\
\hline $\mathrm{E}$ coli $\mathrm{K}-12$ & SAKFKKSARTVGDVLGKYHPHGDSACYEAMVLMAQPFSYRYPLVDGQGNW \\
\hline QS_12_parc & 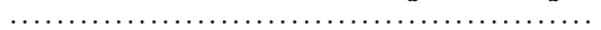 \\
\hline QS_26_parc & $\ldots \ldots \ldots \ldots \ldots \ldots \ldots$ \\
\hline QS 31 parc & . $\ldots \ldots \ldots \ldots \ldots \ldots$ \\
\hline QS_32_parc & 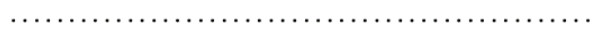 \\
\hline QS_38_parc & 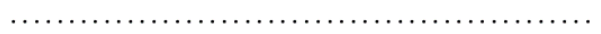 \\
\hline QS_39_parc & 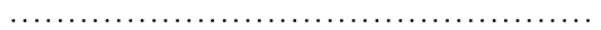 \\
\hline $\mathrm{E} \overline{\mathrm{c}} \mathrm{Ol} \overline{\mathrm{i}} \mathrm{PU}-1$ & SAKFKKSARTVGDVLGKYHPHGDSACYEAMVLMAQPFSYRYPLVDGQGNW \\
\hline QR 1 parC & 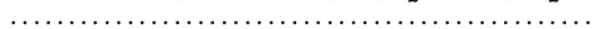 \\
\hline $\mathrm{QR}_{2}$ parc & 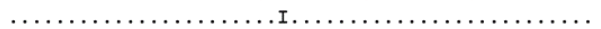 \\
\hline QR_3_parc & \\
\hline $\mathrm{QR}^{-}$parc & $\ldots \ldots \ldots \ldots \ldots \ldots$ \\
\hline QR_5_parc & \\
\hline $\mathrm{QR}^{-} 6$ parc & 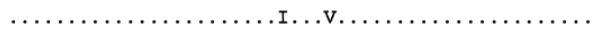 \\
\hline QR_9_parc & 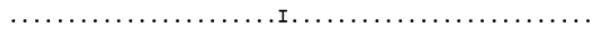 \\
\hline$Q R^{-} 10$ parc & 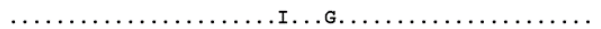 \\
\hline QR_11_parC & \\
\hline$Q R^{-} 13$ parC & 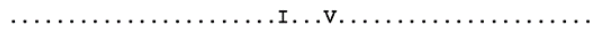 \\
\hline QR_14_parC & \\
\hline$Q R^{-} 15$ parc & 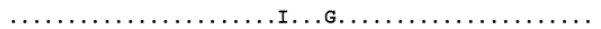 \\
\hline QR_16_parC & 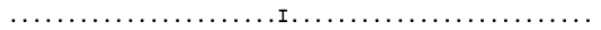 \\
\hline QR_17_parC & 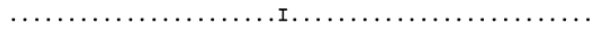 \\
\hline $\mathrm{QR}_{1}^{-}$- parC & 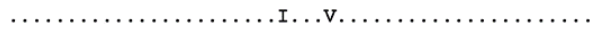 \\
\hline QR_21_parC & 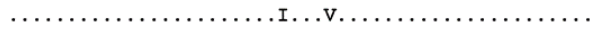 \\
\hline$Q R^{-22}$ parc & $\ldots \ldots \ldots \ldots \ldots \ldots$ \\
\hline $\mathrm{QR}^{-} 23$ parc & 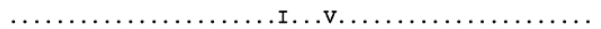 \\
\hline QR_24_parC & \\
\hline QR 27 parc & 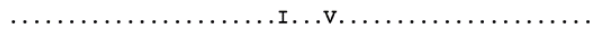 \\
\hline QR 28 parC & 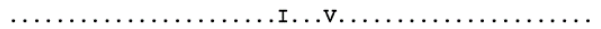 \\
\hline QR_29_parC & 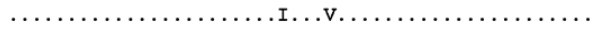 \\
\hline $\mathrm{QR}_{-}^{-} 30$ parc & 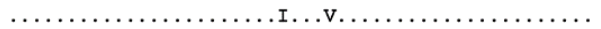 \\
\hline QR_33_parC & ....... \\
\hline QR_34_parC & 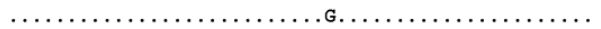 \\
\hline QR_-35_parc & (n.m. \\
\hline QR_36_parC & ....... \\
\hline QR 37 parc & $\ldots \ldots \ldots \ldots$ \\
\hline $\mathrm{QR}_{-}^{-} 40_{-}^{-}$parC & $\ldots \ldots \ldots \ldots, \ldots$ \\
\hline $\mathrm{QR}_{-}^{-} 41_{-}^{-}$parc & \\
\hline QR_42_parc & 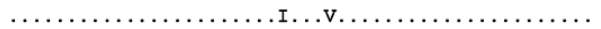 \\
\hline$Q R-43$ parc & ....I. \\
\hline
\end{tabular}

Fig 2: Missense mutations of the $\operatorname{par} C$ gene in the quinolone-resistant (QR) ESBL-E. coli isolates. Partial protein sequence analysis of quinolone-resistant determinant region shows amino acid changes at positions 80 and 84 when compared to the quinolone-sensitive (QS) isolates. E. coli $\mathrm{K} 12$ strain is the reference strain and represents QS strain amino acid sequences, while E. coli PU-1 represents the QR isolates. The numbering of the amino acid residues was confirmed with the reference strain E. coli $\mathrm{K}-12$ strain. (I = isoleucine, $\mathrm{V}=$ valine, $\mathrm{G}=$ glycine)

\section{Correlation between GyrA and ParC mutations and MIC of ciprofloxacin}

A Pearson's correlation coefficient test result revealed that there was a moderate correlation between the number of amino acid mutations in the gyr $A$ gene and MIC levels of ciprofloxacin and it was statistically significant $(r=.646, p=0.00006)$. Similarly, a moderate, and significant correlation was found between the number of mutations in the parC gene and MIC levels of ciprofloxacin $(\mathrm{r}=.504, \mathrm{p}=.003)$. The test also revealed that the increase in par $C$ gene mutations was strongly and significantly associated with an increase in gyr $A$ gene mutations $(r=.730, p=.000002)$ (Figure 3).

All $32 \mathrm{QR}$ isolates except one revealed at least one mutation in $\operatorname{gyr} A$ and/or parC. The majority of the 
isolates $(40.6 \%)$ were shown to carry double mutations in both gyrA (Ser83Leu/Asp87Asn) and parC (Ser80Ile/ Glu84Gln), which were associated with a MIC of $>32$ $\mathrm{ug} / \mathrm{ml}$ level of ciprofloxacin MIC (Table 2). The isolates which possessed double mutations in codons 83 and 87 of gyrA displayed a high level of resistance to ciprofloxacin (MICs; 6-32 $\mu \mathrm{g} / \mathrm{ml}$ ). Double mutations (Ser83Leu/Asp87Asn) in gyrA with additional mutation of types Ser80Ile or Ser80Ile/Glu84Val in parC also resulted in a high level of resistance to ciprofloxacin (MIC $\geq 32 \mu \mathrm{g} / \mathrm{ml}$ ).

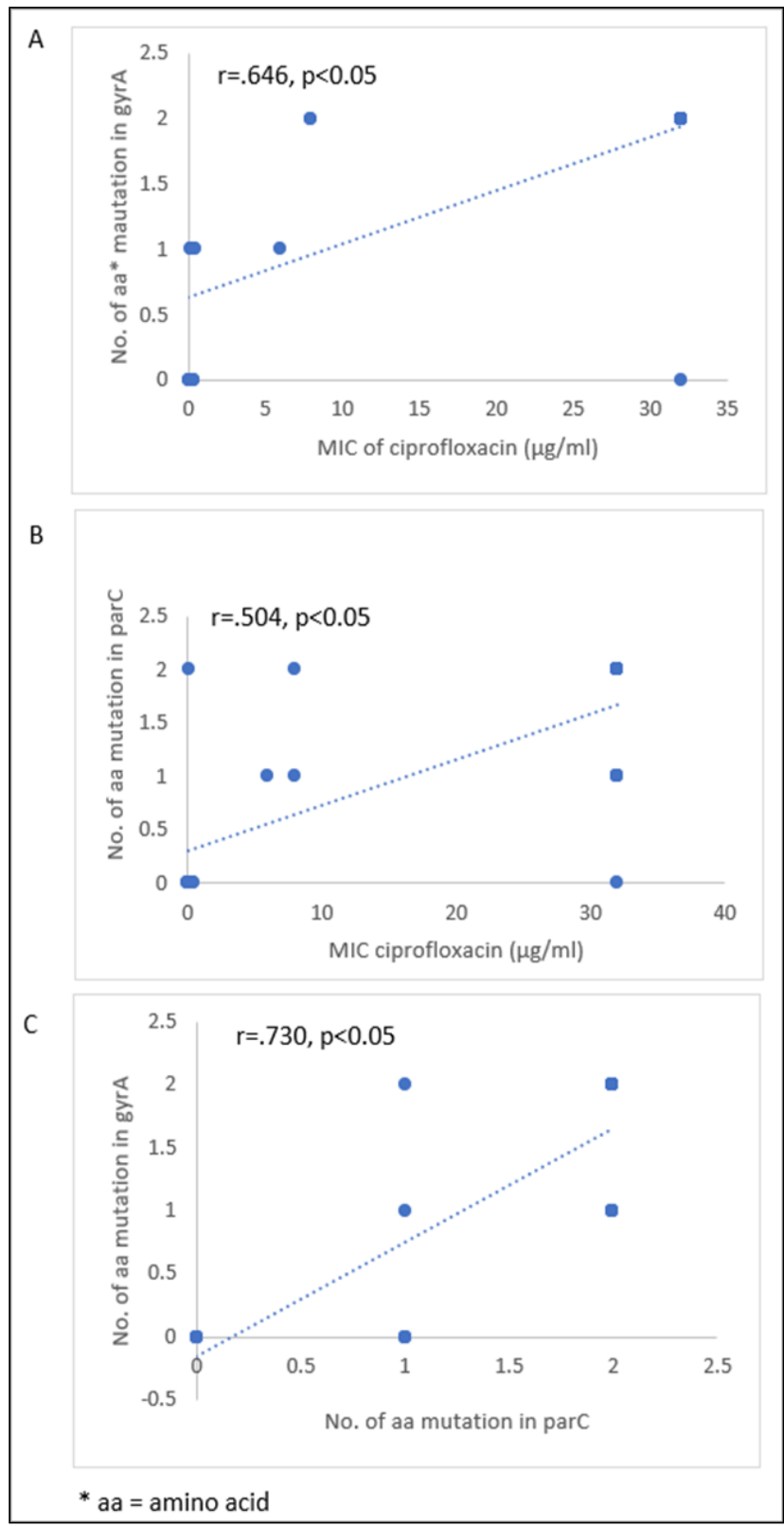

Fig 3: Correlation between mutations in QRDR of the A) gyrA gene and ciprofloxacin MIC, B) parC genes and ciprofloxacin MIC and C) gyrA gene and $\mathrm{parC}$ gene.
Table 2. Summary of amino acid substitutions in the quinolone-resistant determining region (QRDRs) of gyrA and parC genes in the quinoloneresistant (QR) ESBL-E. coli isolates with the corresponding minimum inhibitory concentrations (MICs) of ciprofloxacin (CIP)

\begin{tabular}{|c|c|c|c|}
\hline \multirow{2}{*}{$\begin{array}{l}\text { MIC CIPa } \\
(\mathrm{ug} / \mathrm{ml})\end{array}$} & \multicolumn{2}{|c|}{ Genes } & \multirow{2}{*}{ Isolate ID } \\
\hline & gyrA & $\operatorname{par} C$ & \\
\hline 32 & - & - & 4 \\
\hline 0.125 & Ser83Leu & $\begin{array}{l}\text { Glu84Gln/ } \\
\text { Val144Met }\end{array}$ & 34 \\
\hline 0.25 & Ser83Leu & & $1,35,36$ \\
\hline 0.38 & Ser83Leu & & 33 \\
\hline 0.5 & Ser83Leu & & 37 \\
\hline 6 & Ser83Leu & Ser80Ile & 9 \\
\hline 8 & $\begin{array}{l}\text { Ser83Leu/ } \\
\text { Asp87Asn }\end{array}$ & $\begin{array}{l}\text { Ser80Ile/ } \\
\text { Asn167Thr }\end{array}$ & 41 \\
\hline 8 & $\begin{array}{l}\text { Ser83Leu/ } \\
\text { Asp87Asn }\end{array}$ & Ser80Ile & 2 \\
\hline$\geq 32$ & $\begin{array}{l}\text { Ser83Leu/ } \\
\text { Asp87Asn }\end{array}$ & Ser80Ile & $3,14,16,17,21$ \\
\hline$\geq 32$ & $\begin{array}{l}\text { Ser83Leu/ } \\
\text { Asp87Tyr }\end{array}$ & Ser80Ile & 43 \\
\hline$\geq 32$ & $\begin{array}{l}\text { Ser83Leu/ } \\
\text { Asp87Asn }\end{array}$ & $\begin{array}{l}\text { Ser80Ile/ } \\
\text { Glu84Gln }\end{array}$ & $10,11,15$ \\
\hline$\geq 32$ & $\begin{array}{l}\text { Ser83Leu/ } \\
\text { Asp87Asn }\end{array}$ & $\begin{array}{l}\text { Ser80Ile/ } \\
\text { Glu84Gln }\end{array}$ & $\begin{array}{l}5,6,13,19,22,23,24 \\
, 27,28,29,30,40,42\end{array}$ \\
\hline
\end{tabular}

a CIP resistance value, $\geq 4 \mu \mathrm{g} / \mathrm{ml}$

\section{DISCUSSION}

We focused on the genetic mechanisms of quinolone resistance in ESBL-producing E. coli isolates from our local community which was obtained from a tertiary hospital in Kuantan. The findings were analysed alongside the antibiotic susceptibility profile to commonly used antibiotics. Of note, during the period of the study, nalidixic acid (NA) was used as a surrogate antibiotic for AST, however, it has no longer a recommended treatment option due to high resistance rates in E. coli. As observed in this study, all $32 \mathrm{QR}$ isolates showed $100 \%$ resistance to NA (Table 1).

As expected, most QR ESBL-E. coli isolates possessed mutations in the QRDR of the gyrA gene followed by parC. This implies that mutations in the gyr $A$ are the most common mechanism of quinolones and fluoroquinolones (FQs) resistance followed by the parC mutations. Most of the mutations lead to the alteration of the amino acid sequence of the gyrA and parC which may attribute to phenotypic quinolone resistance. However, the reasons for the distribution of these mutation frequencies and locations are not yet well 
known. Furthermore, double mutations in gyrA were more common than those of parC. This finding has been supported by a similar study reported from our neighbouring country, Thailand, which showed a higher occurrence of Ser83Leu mutation in $g y r A$ in their isolates $(89.1 \%)$ when compared to the parC gene $(82.8 \%) .{ }^{19}$ Another similar study in India by Bansal et al, reported that $98.1 \%$ of their QR-E. coli isolates possessed mutation in gyr $A$ and $83.3 \%$ in par $C$ gene. ${ }^{20}$ Mutations in these two chromosomal genes would highlight one of the intrinsic pathways of quinolone and FQs resistance among $E$. coli. As these mutations are so common, thus, developing a kit to detect their presence is worthy, for rapid detection and evaluation of quinolone resistance.

The number and pattern of mutations particularly in gyr $A$, either single or double, are important sequential events in stepping up the quinolone resistance. Our study showed that a single Ser83Leu mutation of gyrA was associated significantly with high-level resistance to NA (MIC $\geq 256 \mu \mathrm{g} / \mathrm{ml}$ ) but may not to ciprofloxacin (MIC ranged from 0.25 to $0.5 \mu \mathrm{g} / \mathrm{ml}$ ). However, double mutations in $\operatorname{gyr} A$ (Ser83Leu/Asp87Asn) were significantly associated with higher ciprofloxacin MIC levels $(\geq 32 \mu \mathrm{g} / \mathrm{ml})$ [Pearson correlation $(\mathrm{r}=.646, \mathrm{p}=$ 0.000)] and this change was considered to play the initial step towards higher FQs resistance. Furthermore, combinations of point mutations in gyr $A$ and $\operatorname{par} C$ were also required to generate a high level of resistance to FQs. The third most observed pattern of mutations was the combination of double mutations in $g y r A$ and double mutations in parC (Ser83Leu/Asp87Asn and Ser80Ile/Glu84Val). So far, these point mutations in the QRDR of gyrA and parC genes have shown that resistance to FQs increased stepwise with the accumulation of these mutations. ${ }^{21}$ In the E-test, the highest concentration for ciprofloxacin on the test strip was $32 \mu \mathrm{g} / \mathrm{ml}$. Therefore, the combination of one or double mutations in $\operatorname{par} C$ with gyr $A$ mutations may have demonstrated different ciprofloxacin MIC levels if performed with higher ciprofloxacin concentrations.

We found one isolate (QR-4) was highly resistant to ciprofloxacin (MIC, $\geq 32 \mu \mathrm{g} / \mathrm{ml}$ ) but did not have any amino acid alteration either in $\operatorname{gyr} A$ or in $\operatorname{par} C$. The bacteria might undergo different quinolone resistance mechanisms such as plasmid-mediated which targeting protein protecting $q n r$ genes, efflux pump overexpression $O q \times A B$ genes, or drug modifying encoding enzymes. This finding would suggest the other mode of mechanisms may also confer a high resistance but at a very low rate. ${ }^{8}$

In terms of antibiotic susceptibility profile, all the QR ESBL-E. coli isolates were also MDR bacteria. These pathogens, however, were susceptible to carbapenems despite the low level of resistance $(0.7 \%)$ to ertapenem (a member of carbapenems). Thus, carbapenems are one of the last resorts for treating QR ESBL-E. coli infections but cautious and restricted use of these drugs is recommended. We found that QR ESBL-E. coli showed high resistance rates to most penicillin, except piperacillin-tazobactam (PTZ). Evidence from clinical trials in adults has shown that PTZ is an effective treatment for patients with urinary tract infections and other systemic infections such as respiratory tract infections, intra-abdominal infections, and febrile neutropenia. 22,23

Furthermore, QR ESBL-E. coli also showed 100\% susceptibility to amikacin and colistin and thus they also could be used as the last option drug against QR ESBLE. coli infection. Interestingly, resistance to gentamicin and trimethoprim-sulfamethoxazole were much higher in QR ESBL-E. coli (25\% and 75\%, respectively) than QS ESBL-E. coli (0\% and 33.3\%) isolates. This finding indicates that isolates showing resistance to quinolones and FQs may carry resistance genes to aminoglycosides and other antimicrobials as well.

In this study, we did not investigate the further presence of $\beta$-lactamase genes among the studied isolates. However, a similar study had been conducted before on Enterobacteriaceae bacteria isolated from the same population (HTAA). ${ }^{24}$ In the study, ESBL-K. pneumoniae and E. coli isolates showed evidence of ESBL genes, namely bla $a_{C T M-M}$, blaTEM, blasHV, which $28 \%$ of 50 ESBL-positive isolates carrying the three ESBL genes.

In conclusion, mutations in gyr $A$ and $\operatorname{par} C$ genes occurred in most of the QR ESBL- producing E. coli isolates, which may contribute to the development of multi-drug resistant bacteria. The resistance to ciprofloxacin revealed a high correlation with the accumulation of mutations in the QRDR of $\operatorname{gyr} A$ and 
parC genes. Several antimicrobial agents commonly recommended for the treatment of $E$. coli infections were still effective against them in-vitro. This study highlighted the importance of DNA sequencing analysis in determining and understanding the mechanism of actions of quinolone resistance.

\section{Authors' Contributions}

Rahmatullah S. performed laboratory tests, compiled the results, and drafted the manuscript. Mahmud M.I.A.M. and Hamzah A.H designed the study, made the critical revision of the manuscript. Hamzah A.H. helped in bioinformatics and data analysis. Mahmud M.I.A.M. Roesnita B. gave the clinical inputs and logistic supports.

\section{ACKNOWLEDGEMENTS}

This study was financially supported by the Ministry of Higher Education Afghanistan through Higher Education Development Project and International Islamic University Malaysia IIUM. We would like to thank Sr. Siti Nurliyana Binti Ahmad, Medical Technologist, HTAA, for her cooperation in bacterial isolate collection.

\section{Disclosure Statement}

No competing financial interests exist.

\section{REFERENCES}

1. Santos ACM, Santos FF, Silva RM, Gomes TAT. Diversity of hybrid- and heteropathogenic Escherichia coli and their potential implication in more severe diseases. Front Cell Infect Microbiol. 2020;10:339.

2. Breijyeh Z, Jubeh B, Karaman R. Resistance of gram-negative bacteria to current antibacterial agents and approaches to resolve it. Molecules. 2020;25:1340.

3. Nakamura K, Kaneko M, Abe Y, Yamamoto N, Mori H, Yoshida A, et al. Outbreak of extendedspectrum $\beta$-lactamase-producing Escherichia coli transmitted through breast milk sharing in a neonatal intensive care unit. J Hosp Infect. 2016;92:42-6.

4. Muzslay M, Moore G, Alhussaini N, Wilson APR.
ESBL-producing gram-negative organisms in the healthcare environment as a source of genetic material for resistance in human infections. J Hosp Infect. 2017;95:59-64.

5. Rohaidah H, Fairuz A, Hana FZ et al. NATIONAL ANTIBIOTIC RESISTANCE SURVEILLANCE REPORT 2017. Antibiotic Resistance Surveillance Reference Laboratory, Bacteriology Unit, Infectious Diseases Research Centre, Institute for Medical Research, Kuala Lumpur Malaysia. 2017.

6. Al-Marzooq F, Mohd Yusof MY, Tay ST. Molecular analysis of ciprofloxacin resistance mechanisms in Malaysian ESBL-producing Klebsiella pneumoniae isolates and development of mismatch amplification mutation assays (MAMA) for rapid detection of gyrA and parC mutations. Biomed Res Int. 2014.2014:601630

7. Bush NG, Diez-Santos I, Abbott LR, Maxwell A. Quinolones: Mechanism, lethality and their contributions to antibiotic Resistance. Molecules. 2020;25:5662.

8. Huang SN, Michaels SA, Mitchell BB, et al. Exonuclease VII repairs quinolone-induced damage by resolving DNA gyrase cleavage complexes. Sci Adv. 2021;7:eabe0384.

9. Ruiz J. Transferable mechanisms of quinolone resistance from 1998 Onward. Clin Microbiol Rev. 2019;32:e00007-19.

10. Wang P, Hu L, Hao Z. Palmatine is a plasmidmediated quinolone resistance (PMQR) inhibitor that restores the activity of ciprofloxacin against QnrS and AAC(6')-Ib-cr-producing Escherichia coli. Infect Drug Resist. 2020;13:749-759.

11. Singh T, Singh PK, Dar SA, et al. Changing paradigm of antibiotic resistance amongst Escherichia coli isolates in Indian pediatric population. PLoS One. 2019;14:e0213850.

12. Dehbanipour R, Khanahmad H, Sedighi M, Bialvaei AZ, Faghri J. High prevalence of fluoroquinolone-resistant Escherichia coli strains isolated from urine clinical samples. J Prev Med Hyg. 2019;60:E25-E30.

13. Nouri R, Ahangarzadeh Rezaee M, Hasani A, Aghazadeh M, Asgharzadeh M. The role of gyrA and parC mutations in fluoroquinolones-resistant Pseudomonas aeruginosa isolates from Iran. Braz J Microbiol. 2016;47:925-930. 
14. Cheng P, Yang Y, Li F, et al. The prevalence and mechanism of fluoroquinolone resistance in Escherichia coli isolated from swine farms in China. BMC Vet Res. 2020;16:258.

15. Piekarska K, Wołkowicz T, Zacharczuk K, et al. Co-existence of plasmid-mediated quinolone resistance determinants and mutations in gyrA and parC among fluoroquinolone-resistant clinical Enterobacteriaceae isolated in a tertiary hospital in Warsaw, Poland. Int J Antimicrob Agents. 2015;45:238-43.

16. Fazlul MKK, Rashid SS, Nazmul MHM, et al. A clinical update on antibiotic resistance gramnegative bacteria in Malaysia - A review. J Int Pharm Res. 2018;45:270-83.

17. Clinical and Laboratory Standards Institute. Performance Standards for Antimicrobial Susceptibility Testing; Twenty-Seventh Informational Supplement. CLSI Document M100 -S27.;2017.

18. Hu YS, Shin S, Park YH, Park KT. Prevalence and mechanism of fluoroquinolone resistance in Escherichia coli isolated from swine feces in Korea. J Food Prot. 2017;80:1145-51.

19. Onseedaeng S, Ratthawongjirakul P. Rapid detection of genomic mutations in gyrA and parC genes of Escherichia coli by multiplex allele specific polymerase chain reaction. J Clin Lab Anal. 2016;30:947-55.

20. Bansal S, Tandon V. Contribution of mutations in DNA gyrase and topoisomerase IV genes to ciprofloxacin resistance in Escherichia coli clinical isolates. Int J Antimicrob Agents. 2011;37:253-55.

21. Ching C, Zaman MH. Development and selection of low-level multi-drug resistance over an extended range of sub-inhibitory ciprofloxacin concentrations in Escherichia coli. Sci Rep. 2020;10:8754.

22. Gerlach AT, Wenzler E, Hunt LN, Bazan JA, Bauer KA. Pharmacokinetic/pharmacodynamic predictions and clinical outcomes of patients with augmented renal clearance and Pseudomonas aeruginosa bacteremia and/or pneumonia treated with extended infusion cefepime versus extended infusion piperacillin/tazobactam. Int J Crit Illn Inj Sci. 2019;9:138-143.

23. Thønnings S, Jansåker F, Gradel KO, Styrishave B, Knudsen JD. Cefuroxime compared to piperacillin/tazobactam as empirical treatment of Escherichia coli bacteremia in a low Extendedspectrum beta-lactamase (ESBL) prevalence cohort. Infect Drug Resist. 2019;12:1257-1264.

24. Mahdi Yahya Mohsen S, Hamzah HA, Muhammad Imad Al-Deen M, Baharudin R. Antimicrobial susceptibility of Klebsiella pneumoniae and Escherichia coli with extendedspectrum $\beta$-lactamase associated genes in Hospital Tengku Ampuan Afzan, Kuantan, Pahang. Malaysian J Med Sci. 2016;23:14-20. 